\title{
Morphology and immunology of circulating cells in leukaemic phase of follicular lymphoma
}

\author{
JUNIA V MELO, DANIELE S F ROBINSON, MARIA P DE OLIVEIRA, \\ I W THOMPSON, * I A LAMPERT, * J P NG, † D A G GALTON, D CATOVSKY \\ From the Medical Research Council, Leukaemia Unit and the *Department of Histopathology, Royal \\ Postgraduate Medical School, London, and the †Stobhill General Hospital, Glasgow, Scotland
}

SUMMARY Ten patients with follicular lymphoma presented with a high white cell count (45-220 $\times$ $\left.10^{9} / 1\right)$ which resembled chronic lymphocytic leukaemia (CCL): all had pronounced splenomegaly and, except one, generalised lymphadenopathy. 'The blood lymphocytes were small with scanty cytoplasm, densely condensed nuclear chromatin, and deep clefts originating in sharp angles from the nuclear surface. CLL cells are larger, have more cytoplasm, a different pattern of chromatin condensation, and may have shallow nuclear indentations or foldings rather than clefts. The circulating follicular lymphoma cells had moderate to strong membrane immunoglobulins (SmIg), low mouse (M)-rosettes, strong reactivity with the monoclonal antibody FMC7, and occasional expression of the CD5-antigen; at least one third of cells in each case were positive with anti-cALLa (J5,CD10). Half the cases were referred as B-CLL but none had the typical B-CLL immunophenotype: weak SmIg, M-rosettes of $>50 \%$, CD5 positive, FMC7 and J5 negative. The diagnosis of follicular lymphoma was confirmed by lymph node biopsy in seven of the 10 cases. The overall response to treatment was poor and five patients died within three years of diagnosis. This aggressive form of follicular lymphoma needs to be distinguished from B-CLL as different management is required.

Follicular lymphoma is the most common type of nonHodgkin's lymphoma (NHL). In the working formulation the agreed designations within the group of low grade NHL are malignant lymphoma, follicular, predominantly small cleaved cell, or mixed small cleaved and large cell.'

Follicular lymphoma cells originate in the germinal centres of lymph nodes and consist of both small cleft lymphocytes or centrocytes and large blasts or centroblasts, with predominance of the former. ${ }^{2}$ Thus in the Kiel classification this tumour is designated centroblastic/centrocytic lymphoma. This lymphoma may evolve to or, more rarely, present in a leukemic phase, and the incidence of such an event varies in different series, ranging from $4.5 \%{ }^{2}$ to $23 \%{ }^{3}$ In the leukaemic form of follicular lymphoma a variable proportion of the peripheral blood lymphocytes exhibit characteristic morphological detail which has been described as "notched-nucleus cell". ${ }^{4}$ The degree of lymphocytosis at presentation is also variable, but rarely exceeds $30 \times 10^{9} / \mathrm{l}^{35}$

Accepted for publication 7 April 1988
Over the past five years we assembled a series of 10 patients with an aggressive form of follicular lymphoma, with advanced clinical features at presentation, and in a leukaemic phase with high white cell counts. In this unusual form of presentation follicular lymphoma can often be mistaken for chronic lymphocytic leukemia (CLL). In this report we describe the features of the disease in patients with follicular lymphoma, with special emphasis on the morphological and immunological characteristics that can help in the differential diagnosis of CLL and other B cell leukaemias.

\section{Patients and methods}

Ten patients with follicular lymphoma in leukaemic phase and white cell counts greater than $40 \times 10^{9} / 1$ were included in this study. Clinical and haematological features selected for analysis comprised sex, age, haemoglobin concentration, platelet count, white cell count, size of palpable liver and spleen and degree of lymph node enlargement, either at presentation or at onset of leukaemic phase, or both. Treatment and follow up data were available for all but one patient. 
Cellular morphological detail was studied by light microscopy on peripheral blood films stained with May-Grünwald Giemsa, and the cytological features in the cases of follicular lymphoma were compared with those of 13 patients with typical CLL and high white cell counts $\left(>100 \times 10^{9} / 1\right)$. In four cases of follicular lymphoma peripheral blood lymphocytes were processed for transmission electron microscopy according to standard techniques. ${ }^{6}$ Briefly, cells were fixed for 30 minutes in $3 \%$ glutaraldehyde in phosphate buffer saline, post-fixed in $1 \%$ osmium tetroxide, and stained in blood with $4 \%$ aqueous uranyl acetate. The cells were pre-embedded in 3\% agar, dehydrated, and embedded in Araldite. Ultrathin sections stained with uranyl acetate and lead citrate were viewed on a Zeiss 20 electron microscope. Lymph node biopsy specimens and bone marrow aspirates were assessed histologically on hematoxylin and eosin stained section of biopsy specimens or necropsy material embedded in paraffin wax.

Immunophenotyping was carried out in peripheral blood mononuclear cell suspension obtained by density gradient separation in Lymphoprep (Nyegaard, Oslo, Norway). The following markers were investigated: formation of rosettes with sheep erythrocytes (E-rosettes) and mouse erythrocytes (M-rosettes); surface immunoglobulin ( $\mathrm{SmIg}$ ) by direct immunofluorescence by means of fluorescein isothirocyanateconjugated (FITC) $\mathrm{F}(\mathrm{ab})_{2}$ fragment of goat antihuman $\kappa$ and $\lambda$ chains (Dynatech Lab, Billingshurst, Kent); and leucocyte differentiation antigens detected by indirect immunofluorescence with the following monoclonal antibodies: GRB1 (gift from Professor F Garrido, Granada, Spain), anti-class II MHCantigen; UCHT2 (Seward Laboratories, Bedford), anti-p67 (CD5) antigen; FMC7 (Sera Lab, Crawley Down) which recognises a subpopulation or normal peripheral blood B lymphocytes and most cells in Bprolymphocytic leukaemia (B-PLL) and hairy cell leukemia (HCL) ${ }^{7}$; and J5 (Coulter, Hialeah, Florida)
anti-cALLa (CD10). Second layer reagents consisted of FITC-conjugated $\mathrm{F}(\mathrm{ab})_{2}$ fragment of goat antimouse IgG or IgM (Dynatech Laboratories). Results of the immunofluorescence tests were read by fluorescence microscopy, and the intensity of reaction in cell suspensions was also assessed by readings on a FACS analyzer (Becton Dickinson, Sunnyvale, California).

\section{Results}

CLINICAL AND HAEMATOLOGICAL FEATURES

There were seven men and three women with a mean age of 54 years at diagnosis. The clinical and haematological features are summarised in table 1. The disease presented in leukaemic phase with a high white cell count in all but one patient (case 10), in whom the histological diagnosis of follicular lymphoma was made four years before the white cell count had increased. Five of the patients were referred for immunological studies with the presumptive diagnosis of CLL.

Symptoms at presentation were mainly of weakness and fatigue due to anaemia, night sweats and pruritus, abdominal pain and distension with nausea and vomiting, and the finding of single or multiple enlarged nodes. On physical examination, all but one of the patients had pronounced and generalised lymphadenopathy, with individual lymph nodes measuring from 2 to $8 \mathrm{~cm}$ in diameter. The spleen was palpable in all patients, ranging from 3 to $16 \mathrm{~cm}$ below the left costal margin; a moderate to severe hepatomegaly was also common. Half the patients had anaemia (haemoglobin concentration below $11 \mathrm{~g} / \mathrm{dl}$ ) and thrombocytopenia (platelet count of $<150 \times 10^{9} /$ 1) was observed in seven. The white cell count ranged from 45 to $22 \times 10^{9} / 1$ and was above $100 \times 10^{9} / 1$ in seven of the 10 patients. Lymphoid cells accounted for $86-98 \%$ of the white cell count.

Table 1 Clinical and haematological features of patients with follicular lymphoma

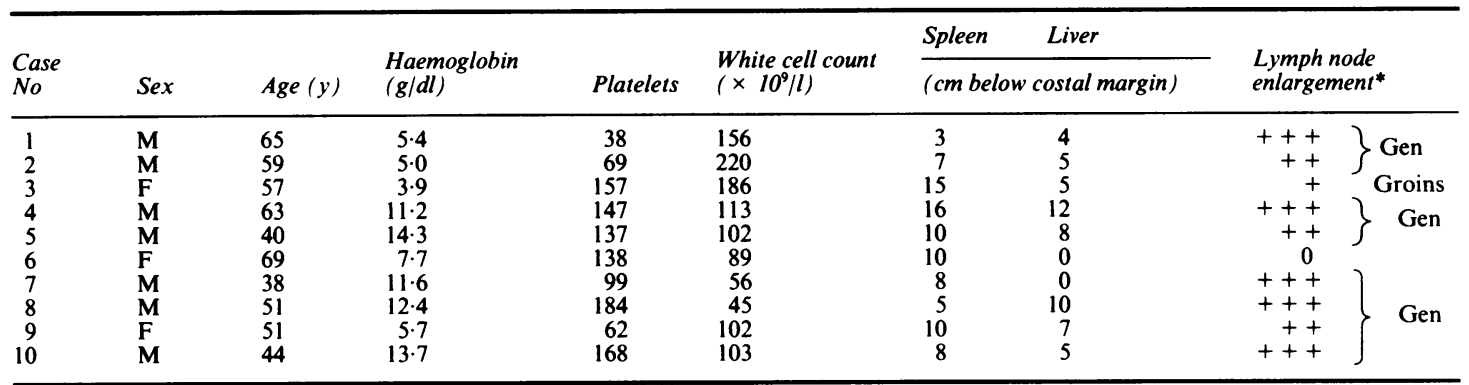

${ }^{*}$ Lymph node enlargement: $0=$ absent; $+=$ minimal (node or nodes $<2 \mathrm{~cm}$ ); $++=$ moderate (nodes $2-4 \mathrm{~cm}$ ); $+++=$ severe (individual nodes $>4 \mathrm{~cm}$ ).

Gen $=$ generalised adenopathy 
CYTOLOGICAL FEATURES

The peripheral blood lymphocytes had a characteristic morphology at light microscopical examination (figs 1 and 2). They were very small with diameters comparable with those of erythrocytes, they had a regular round shape, and little or no heterogeneity in size in most cases. The cytoplasm was scanty and, when visible, consisted of a thin rim confined to between one fourth and one half of the cell circumference; a variable, usually large, proportion of lymphocytes seemed to be devoid of any cytoplasm. The nucleus was also characteristic: the chromatin was homogeneously and heavily condensed and nucleoli were seldom seen. The most distinct feature of these lymphocytes was a pattern of nuclear irregularity represented by the presence of one or two, rarely three, deep clefts, originating from the nuclear surface in sharp angles, and being recognised as very thin lines

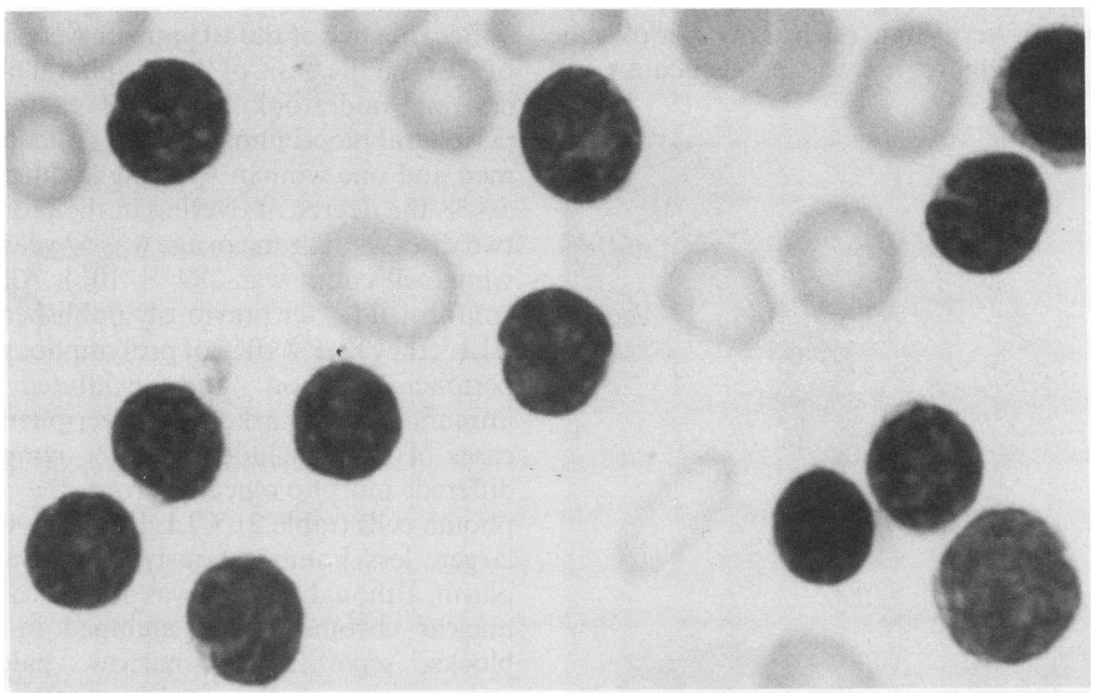

Fig 1 Peripheral blood films of case 2 showing small cells (comparable to red blood cell) with cleft nucleus and almost no visible cytoplasm.

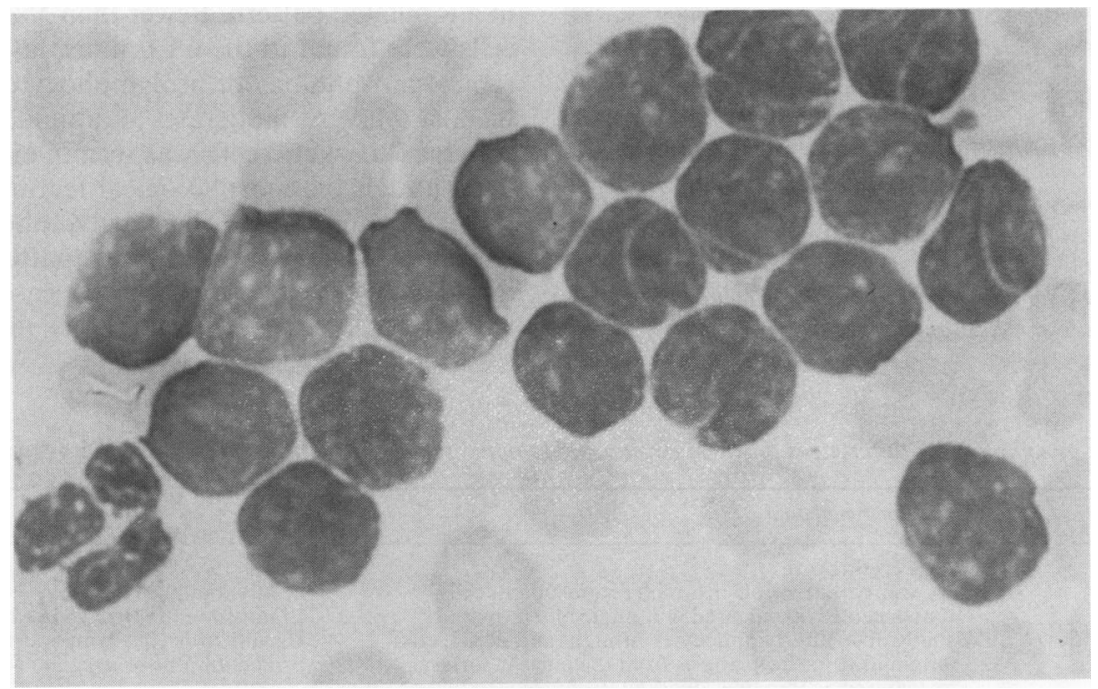

Fig 2 Peripheral film of case 5 showing slightly larger cells than in fig 1 but with homogeneously stained chromatin and distinct nuclear clefts which seem to divide nuclei of some cells in half. 
crossing the chromatin, sometimes appearing to divide the nucleus in two parts (figs 1 and 2). The proportion of small lymphocytes with cleft nuclei varied from less than $10 \%$ to as high as $88 \%$, being greater than $30 \%$ in seven of the 10 cases. In addition to small lymphocytes, a minor population $(<10 \%)$ of large blastic cells with loose chromatin and multiple nucleoli, occasionally with nuclear clefts, was seen in all cases. "Smudge" cells, commonly observed in CLL, were either absent or scanty.

At ultrastructural level (fig 3) the lymphocytes were very small with a very high nuclear to cytoplasmic ratio (N:C). The Golgi region was inconspicuous and

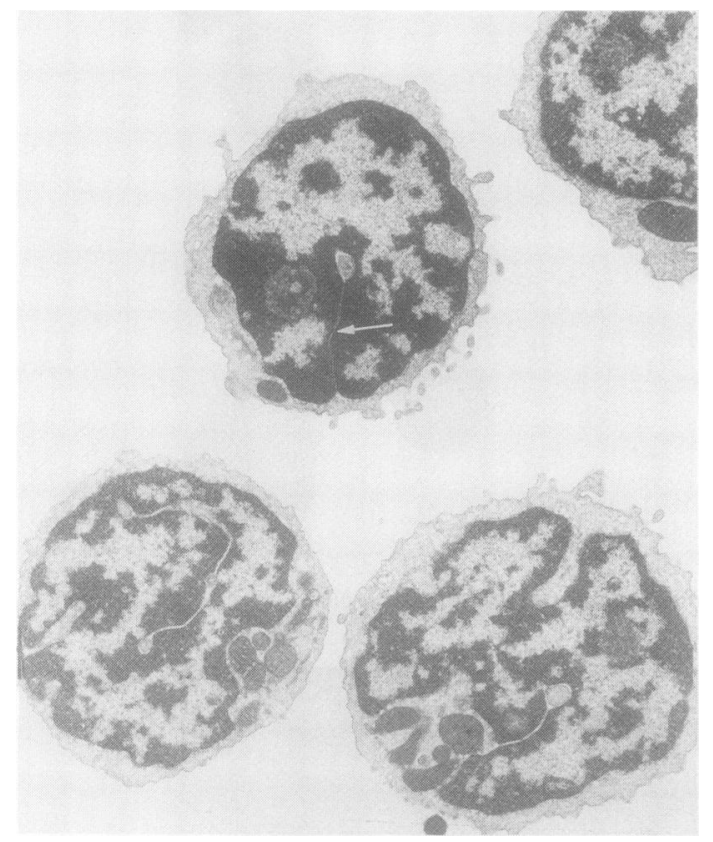

Fig 3 Low power electron micrograph of circulating small cleft lymphocytes from case 2. These cells show high nuclear cytoplasmic ratio and heavily condensed chromatin. Most of these cells show long and very narrow clefts, which may be difficult to visualise at light microscopy level (arrow). there was little development of any other cytoplasmic organelles. The characteristic features of these cells was the presence of one or more nuclear clefts, of variable length, but invariably extremely narrow. Nuclear pockets were common and many cells appeared bi- or multi-lobed. The nuclear chromatin was heavily condensed and a small nucleolus was seen in $20-30 \%$ of cells. About $5-10 \%$ of cells were slightly larger, had a lower $\mathrm{N}: \mathrm{C}$ ratio, greater development of cytoplasmic organelles, and less well condensed chromatin.

Because five of the 10 patients were referred as cases of CLL on the basis of the peripheral blood appearances, we undertook a careful examination of the peripheral blood films from 13 patients with CLL (12 men and one woman with high white cell counts) to assess the degree of overlap in the morphology of the two diseases. The mean age was 67 years and the mean white cell count was $289 \times 10^{9} / 1$. All these patients conformed to our previously published criteria for B$\mathrm{CLL}^{8}$; they had $<10 \%$ of prolymphocytoid cells in the peripheral blood and exhibited characteristic immunological markers. The peripheral blood in the cases of CLL included $89-97 \%$ lymphocytes which differed morphologically from the follicular lymphoma cells (table 2). CLL lymphocytes were usually larger, less homogeneously round, and their cytoplasm, although scanty, was always easily visible. The nuclear chromatin was clumped in several coarse blocks, separated by narrow, paler areas, and irregularities of the nuclear outline were usually limited to less than $10 \%$ of the lymphocytes and consisted of shallow indentations or irregular foldings in a lobulated pattern. Fewer than $5 \%$ of nucleolated cells were found in the CLL films, and these had the typical morphology of prolymphocytoid ${ }^{8}$ rather than blastic cells. A moderate to abundant number of smudge ("basket") cells was seen in every case.

Although the morphological features described in table 2 distinguished follicular lymphoma from CLL lymphocytes, exceptions to those patterns were found in both diseases. In two of the cases of CLL the lymphocytes were very small, as most often seen

Table 2 Main morphological differences between circulating lymphocytes from follicular lymphoma and from CLL

\begin{tabular}{|c|c|c|}
\hline Feature & Follicular lymphoma & $C L L$ \\
\hline Cell size & $\leqslant$ One erythrocyte & One to two erythrocytes \\
\hline Cytoplasm & Very scanty, not visible in a high proportion of cells & Scanty, but always visible \\
\hline Chromatin & Homogeneously condensed in a single block & Clumped in multiple coarse blocks \\
\hline Nuclear irregularities & $\begin{array}{l}\text { Usually in }>30 \% \text { lymphocytes: straight and deep clefts } \\
\text { originating in sharp angles from the nuclear surface, } \\
\text { recognised as thin lines dividing the nucleus in two or three } \\
\text { parts }\end{array}$ & $\begin{array}{l}\text { Usually in }<10 \% \text { lymphocytes: shallow } \\
\text { indentations or irregular foldings }\end{array}$ \\
\hline $\begin{array}{l}\text { Nucleolated cells } \\
\text { Smudge cells }\end{array}$ & $\begin{array}{l}<10 \% \text {, blastic } \\
\text { Absent or very few }\end{array}$ & $\begin{array}{l}<10 \% \text {, prolymphocytoid } \\
\text { Abundant }\end{array}$ \\
\hline
\end{tabular}


among the follicular lymphoma series, and in one of them $12 \%$ of these cells showed the pattern of nuclear clefting described for follicular lymphoma lymphocytes. On the other hand, three cases of follicular lymphoma had only $5 \%$ to $20 \%$ easily recognisable cleft cells, although all the other morphological characteristics of follicular lymphoma described above were present.

\section{IMMUNOLOGICAL MARKERS}

The immunophenotype of the peripheral blood lymphocytes in the 10 cases of follicular lymphoma and in the 13 patients in the CLL group is shown in table 3. In follicular lymphoma the malignant cells expressed monoclonal SmIg ( $\kappa$ isotope in four and $\lambda$ isotype in six cases), with moderate to strong staining. Less than $30 \%$ of the cells formed M-rosettes in eight of nine cases tested and, conversely, more than $40 \%$ of the cells reacted with FMC7 in seven of eight cases. Only case 10 had two of the features regarded as typical of B-CLL-high M-rosettes and low expression of FMC7. Significant expression of the p67 (CD5) antigen ( $>50 \%$ of the cells) was found only in two of nine cases studied, but none of the other marker features of B-CLL was seen in those cells (cases 1 and 2). The reactivity with $\mathrm{J} 5$ (CD10) ranged from $30 \%$ to $97 \%$ of the cells in this series. In B-CLL the lymphocytes usually expressed low density SmIg and CD5 antigen, high M-rosette formation (68 (SD) $24 \%$ ), and low reactivity with FMC7. The cALLa (CD10) antigen was not detected on the cell membrane in the three cases tested.

\section{LYMPH NODE AND BONE MARROW HISTOLOGICAL} RESULTS

Lymph node histological results were available in seven cases: four from biopsied material and three from necropsy specimens. One patient was lost to follow up, one refused surgical intervention, and histological analysis at necropsy was not available in another. All lymph nodes examined were affected by NHL (follicle centre cell type). Two (cases 2 and 4) showed malignant lymphoma, diffuse, small and large cell (diffuse centroblastic/centrocytic pattern), and the remainder showed follicular lesions, four of predominantly small cleaved cell type (cases 3, 7, 9 and 10) (fig 4), and one of mixed small cleaved and large cell type (case 8). The extent of follicularity in these biopsy specimens was inversely related to the degree of retention of interfollicular preservation of sinus and post-capillary venule architecture. In the most extreme example (case 9) the malignant infiltrate seemed to selectively affect follicles, leaving almost normal interfollicular regions. Bone marrow biopsy specimens were available in seven cases, all of which showed infiltrates. The commonest pattern was a heavy infiltrate with both a paratrabecular and a diffuse component (cases $1,4,5,8)$ (fig 5). Two cases ( 3 and 10)

Table 3 Immunological markers of circulating lymphocytes in two series of patients

\begin{tabular}{|c|c|c|c|c|c|c|c|c|}
\hline \multirow{2}{*}{$\begin{array}{l}\text { Diagnosis } \\
\text { (series) }\end{array}$} & \multirow{2}{*}{$\begin{array}{l}\text { Case } \\
\text { No }\end{array}$} & \multirow[b]{2}{*}{$S m I g^{*}$} & $\begin{array}{l}\text { Mouse } \\
\text { rosettes }\end{array}$ & $\begin{array}{l}\text { Class II } \\
M H C\end{array}$ & $\begin{array}{l}\text { CD5 } \\
(p 67)\end{array}$ & $F M C 7$ & $\begin{array}{l}C D 10 \\
(c A L L a)\end{array}$ & $\begin{array}{l}\text { Sheep- } \\
\text { rosettes }\end{array}$ \\
\hline & & & \multicolumn{6}{|c|}{ (per cent positive cells) } \\
\hline $\begin{array}{l}\text { Follicular } \\
\text { lymphoma: }\end{array}$ & $\begin{array}{r}1 \\
2 \\
3 \\
4 \\
5 \\
6 \\
7 \\
8 \\
9 \\
10\end{array}$ & $\begin{array}{l}\lambda+++ \\
\lambda+++ \\
\kappa++ \\
\lambda++ \\
\lambda+++ \\
\kappa+++ \\
\kappa++ \\
\lambda++ \\
\kappa++ \\
\lambda++\end{array}$ & $\begin{array}{c}3 \\
2 \\
27 \\
0 \\
24 \\
20 \\
\text { NT } \\
6 \\
1 \\
87\end{array}$ & $\begin{array}{r}45 \\
98 \\
\text { NT } \\
70 \\
100 \\
94 \\
61 \\
73 \\
90 \\
80\end{array}$ & $\begin{array}{c}83 \\
91 \\
\text { NT } \\
28 \\
0 \\
7 \\
\text { NT } \\
19 \\
0 \\
3\end{array}$ & $\begin{array}{l}92 \\
82 \\
\text { NT } \\
50 \\
98 \\
87 \\
\text { NT } \\
45 \\
85 \\
9\end{array}$ & $\begin{array}{l}78 \\
79 \\
\text { NT } \\
30 \\
97 \\
96 \\
50 \\
\text { NT } \\
51 \\
64\end{array}$ & $\begin{array}{r}3 \\
1 \\
9 \\
3 \\
1 \\
1 \\
8 \\
14 \\
5 \\
2\end{array}$ \\
\hline CLL: & $\begin{array}{r}1 \\
2 \\
3 \\
4 \\
5 \\
6 \\
7 \\
8 \\
9 \\
10 \\
11 \\
12 \\
13\end{array}$ & $\begin{array}{l}\kappa \pm \\
\kappa \pm \\
\kappa+ \\
\kappa+ \\
\kappa+ \\
\lambda \pm \\
i \pm \\
\kappa \pm \\
\kappa \pm \\
\kappa \pm \\
\kappa \pm \\
\kappa \pm \\
\text { Negative }\end{array}$ & $\begin{array}{l}74 \\
72 \\
73 \\
88 \\
89 \\
74 \\
80 \\
31 \\
65 \\
75 \\
49 \\
14 \\
98\end{array}$ & $\begin{array}{r}97 \\
62 \\
95 \\
89 \\
74 \\
98 \\
71 \\
90 \\
81 \\
\text { NT } \\
82 \\
74 \\
82\end{array}$ & $\begin{array}{l}99 \\
57 \\
90 \\
84 \\
73 \\
96 \\
85 \\
97 \\
6 \\
73 \\
89 \\
98 \\
97\end{array}$ & $\begin{array}{r}0 \\
0 \\
0 \\
7 \\
0 \\
13 \\
26 \\
5 \\
4 \\
9 \\
0 \\
11 \\
4\end{array}$ & $\begin{array}{c}\text { NT } \\
\text { NT } \\
\text { NT } \\
\text { NT } \\
\text { NT } \\
0 \\
\text { NT } \\
\text { NT } \\
0 \\
\text { NT } \\
\text { NT } \\
\text { NT } \\
0\end{array}$ & $\begin{array}{l}7 \\
3 \\
4 \\
0 \\
3 \\
8 \\
3 \\
2 \\
6 \\
2 \\
3 \\
1 \\
0\end{array}$ \\
\hline
\end{tabular}

*SmIg.

Intensity of reaction expressed as: $\pm=$ very weak; $+=$ weak $++=$ moderate $;+++=$ strong. 
showed a much lesser degree of disease, with preservation of fat spaces, but a similar paratrabecular and diffuse pattern. Case 10 also showed occasional apparently intramedullary aggregates, and case 2 showed intramedullary aggregates, and a diffuse pattern with no definite paratrabecular infiltrates. The cytology of the marrow infiltrates was similar to that of the lymph nodes-that is, small cleaved cells predominated.

\section{TREATMENT AND FOLLOW UP}

Each patient in this series was treated by the referring physician and therefore the therapeutic regimens varied. Five patients were dead at the time of this report and four were reported to be alive at the closing date for this analysis; one was lost to follow up. Five patients survived less than three years from diagnosis. One (case 2) died within 24 hours of diagnosis; two others (cases 4 and 7) did not respond to treatment and died one and five months after presentation. Two patients (cases 1 and 3) had a partial remission but relapsed within one and a half years; they survived 31 and 35 months, respectively.

Five patients achieved a complete remission with combination chemotherapy. Two of them (cases 5 and 9) relapsed eight months after treatment was discontinued. Case 5 had a new complete remission continuing 15 months from diagnosis and case 9 is alive with active disease 29 months after clinical presentation. Cases 6 and 8 had complete remission which persisted for 10 months but case 6 was lost to follow up. Case 10 had a complete remission which lasted 16 months. A partial response was subsequently achieved but a leukaemic phase evolved four years from diagnosis and this responded partially. He is alive with persistent disease 57 months from diagnosis and six months after the leukaemic phase had become apparent.

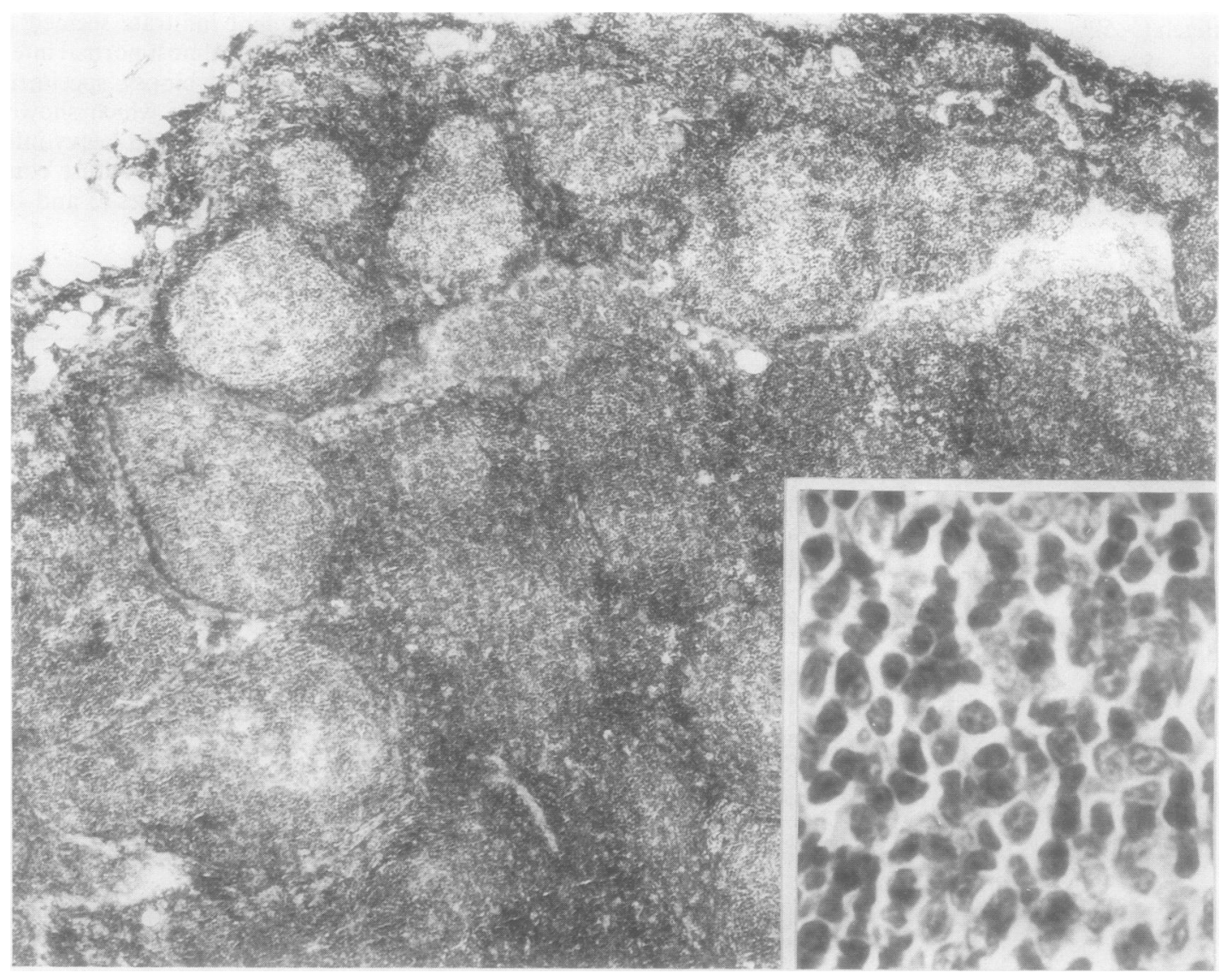

Fig 4 Section of lymph node biopsy specimen of case 10. Follicular lymphoma with predominantly small cleaved cells. 


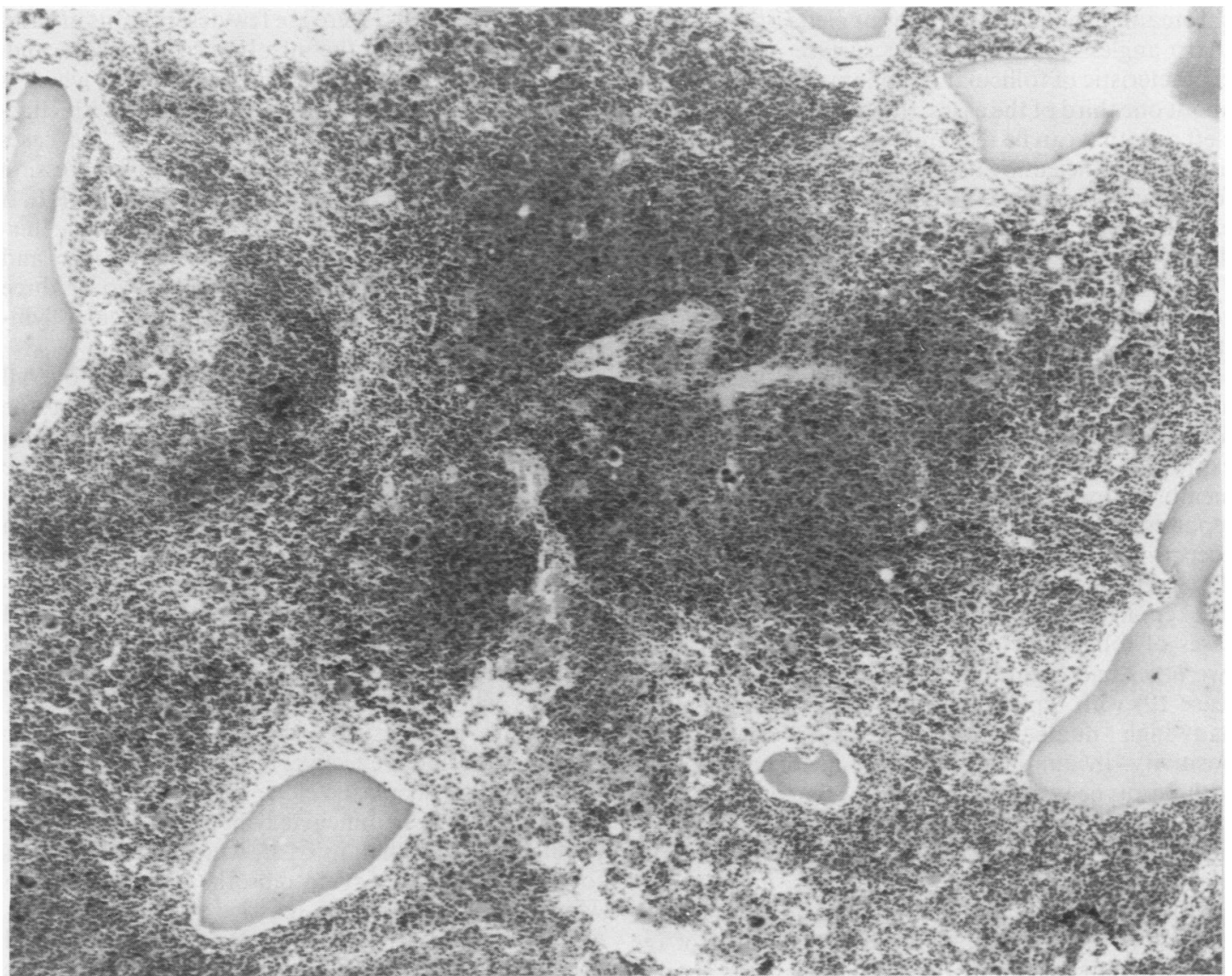

Fig 5 Bone marrow biopsy specimen of case 5 showing diffuse and paratrabecular infiltration; haemopoiesis is confined to intramedullary regions.

\section{Discussion}

The diagnosis of lymphoma in a patient with a high white cell count is rarely considered if the circulating cells resemble, at first sight, the small mature looking lymphocytes of CLL. In fact, half the patients in the present series and several others in Spiro's survey ${ }^{3}$ had been referred as cases of CLL, and the diagnosis would have been accepted if lymph node biopsy and marker studies had not been carried out.

Several features suggest follicular lymphoma rather than CLL in cases with high white cell counts. The mean age of incidence of follicular lymphoma is at least 10 years below that for CLL (54 (11) v 67 (8) respectively, in the present series) and, as pointed out previously, ${ }^{3}$ lymph node biopsy is always necessary in patients below age 40 , when CLL is uncommon. The sex ratio in some series of follicular lymphoma has shown an excess of women, ${ }^{3}$ though in our small series the male:female ratio $(2 \cdot 3: 1)$ resembled that of large CLL series. ${ }^{8-10}$

The clinical features of patients with follicular lymphoma in leukaemic phase are similar to those of CLL, but the massive lymph node enlargement seems to be more conspicuous in follicular lymphoma. On the other hand, all our patients with follicular lymphoma had clinically important splenomegaly, and this perhaps suggests that this diagnosis would seem unlikely in patients with a high white cell count who do not have an enlarged spleen.

The lymphocyte morphology in well prepared peripheral blood films is important in distinguishing CLL from follicular lymphoma with high white cell count. The circulating neoplastic cells in follicular lymphoma and in CLL can be recognised as distinct morphological types on the basis of a combination of features (table 2). The very small size, the scarcity of visible cytoplasm, and the highly condensed nuclear 
chromatin divided by thin lines or clefts originating in sharp angles from the nuclear surface are all highly characteristic of follicular lymphoma lymphocytes. In about one third of the cases, though, the proportion of cleft cells that can be recognised at light microscopical may be insufficient by itself to ascertain a diagnosis of follicular lymphoma, and electron microscopical examination provides additional morphological detail.

The membrane markers of follicular lymphoma cells and CLL lymphocytes are also characteristic (table 3). The follicular lymphoma lymphocyte seems to be immunologically more mature than the CLL cell, as shown by a higher content of SmIg, low M-rosette formation, strong reactivity with FMC7, and the rare expression of the CD5 antigen. In addition, the membrane expression of the cALLa (CD10) antigen is reported to be a hallmark of follicular centre cells," occurring much less often in typical CLL cells-as in the present study. The characteristic composite marker phenotype of B-CLL was not seen in any of the cases of follicular lymphoma studied (table 3); only two cases had high expression of CD5 and only one (case 10) with typical follicular lymphoma histology had high numbers M-rosettes and low FMC7 positivity. In our small series the incidence of $\mathrm{SmIg}$ with $\lambda$ isotype was relatively high, compared with the approximate two- to three-fold predominance of expressing cases $\kappa$ in most CLL series. ${ }^{812}$ Whether the predominance of $\lambda$-expressing clones in follicular lymphoma is another feature of immunological maturity, as suggested previously from studies of Iggene rearrangements in $\mathrm{B}$ cell malignancies ${ }^{13}$ is not presently known. The ultimate diagnostic confirmation of follicular lymphoma and other follicle centre cell types of NHL is seen in the lymph node histology. There is usually no difficulty in making these diagnoses even in predominantly diffuse small and large cell lymphoma. In this series the predominant cell was the small cleaved cell, although mixed small and large cell types were also observed. Bone marrow disease seems to be ubiquitous, and there is usually heavy infiltration with a paratrabecular and diffuse distribution.

Another B cell disorder to consider in the differential diagnosis of follicular lymphoma presenting with high white cell count is "intermediate" lymphocytic or mantle zone NHL. ${ }^{14}$ These cases often present with splenomegaly and have a progressive course; high white cell count of $>50 \times 10^{9} / 1$ has rarely been observed. In common with B-CLL, the cells of intermediate lymphoma express the p67 protein (CD5) and have variable expression of cALLa (CD10). Morphologically, the cells have a condensed nuclear chromatin with slight irregularity and indentation and are of intermediate size. The differential diagnosis from follicular lymphoma includes the morphology of the circulating cells (there are few descriptions of cases in leukaemic phase), the membrane phenotype, and, most importantly, the lymph node histology which is predominantly diffuse or vaguely nodular with effacing of the nodal architecture. ${ }^{14}$ None of the cases included in this report, including those with expression of CD5, had features resembling intermediate NHL. If we consider the three main diagnostic criteria: histology of lymph nodes and bone marrow, markers and morphology, each of our 10 cases had two or three positive criteria for the diagnosis of follicular lymphoma.

The aggressive evolution of the disease and overall poor response to treatment in patients from the present series stand out as considerably different from the natural history of both typical CLL and the commoner form of follicular lymphoma with only moderately high white cell counts. In the latter two disorders the median survival has been reported to be about eight years ${ }^{1015}$ and about five years, ${ }^{135}$ respectively, half the patients in the present study were dead within three years of diagnosis. Although the initial response to treatment was relatively good in those patients who are still alive at the time of writing, remissions were usually short and treatment for relapse was seldom effective.

Perhaps the neoplastic clone in the hyperleucocytic leukaemia form of follicular lymphoma has a higher proliferative rate than in CLL, which would account for the rapid onset of symptoms, the abrupt rise in the white cell count, and the massive organomegaly, as well as for the overall poor response to conventional chemotherapy often effective in CLL. Because of its poor prognosis, it is important that this special presentation of follicular lymphoma is correctly diagnosed, and that lymph node excision is done when the suggestive clinical, haematological, and immunological features we have described are found.

A consistent chromosome abnormality $\mathrm{t}(14 ; 18)$ has been shown in $85 \%$ of cases of follicular lymphoma. ${ }^{16}$ Additional abnormalities seemed to be associated with a worse prognosis. Of interest is the observation that a deletion 13q32 was seen in cases evolving with a leukaemic phase ${ }^{16}$; it is likely that this type of cytogenetic information would further strengthen the characterisation of the leukaemic phase of follicular lymphoma.

We are grateful to the following colleagues for information and for the supply of samples from patients under their care: Drs M Brozovic, J F Burman, T O Kumaran, M Mills, T A J Phaure, G J S Rustin, N E Traub, and Y F Williams.

\section{References}

1 The Non-Hodgkin's Lymphoma Classification Project. National 
Cancer Institute sponsored study of classifications on nonHodgkin's lymphoma. Summary and description of a working formulation for clinical usage. Cancer 1982;49:2112-35.

2 Lennert K. Malignant lymphomas other than Hodgkin's disease. Berlin: Springer-Verlag, 1978:302-46.

3 Spiro S, Galton DAG, Wiltshaw E, Lohmann RC. Follicular lymphoma: a survey of 75 cases with special reference to the syndrome resembling chronic lymphocytic leukaemia. $\mathrm{Br} J$ Haematol 1975;31(suppl II):60-72.

4 Anday GJ, Schmitz HL. Follicular lymphoma with transient leukemic phase. Arch Intern Med 1952;89:621-5.

5 Come SE, Jaffe ES, Andersen JC, et al. Non-Hodgkin's lymphomas in leukemic phase: clinicopathologic correlations. Am J Med 1980;69:667-74.

6 Robinson DSF, Melo JV, Andrews C, Schey SA, Catovsky D. Intracytoplasmic inclusions in B prolymphocytic leukaemia: ultrastructural, cytochemical, and immunological studies. J Clin Pathol 1985;38:897-903.

7 Catovsky D, Melo JV, Matutes E. Biological markers in lymphoproliferative disorders. In: Bloomfield CD, ed. Chronic and acute leukemias in adults. Boston: Martinus-Nijhoff, 1985: 69-112.

8 Melo JV, Catovsky D, Galton DAG. The relationship between chronic lymphocytic leukaemia and prolymphocytic leukaemia. I. Clinical and laboratory features of 300 patients and characterization of an intermediate group. Br J Haematol 1986;63: 377-87.

9 Skinnider LF, Tan L, Schmidt J, Armitage G. Chronic lymphocytic leukemia: a review of 745 cases and assessment of clinical staging. Cancer 1982;50:2951-5.

10 Rai KR, Sawitsky A, Jagathambal K, Gartenhaus W, Phillips E. Chronic lymphocytic leukemia. Med Clin North Am 1984;68: 697-711.

11 Ritz J, Nadler LM, Bhan AK, Notis-McConarty J, Pesando JM, Schlossman SF. Expression of common acute lymphoblastic leukemia antigen (CALLA) by lymphomas of B-cell and T-cell lineage. Blood 1981;58:648-52.

12 Baldini L, Mozzana R, Cortelezzi A, et al. Prognostic significance of immunoglobulin phenotype in B-cell chronic lymphocytic leukemia. Blood 1985;65:340-4.

13 Luzzatto L, Foroni L. DNA rearrangements of cell lineage specific genes in lymphoproliferative disorders. Progr Haematol 1986; 14:303-31.

14 Jaffe ES, Bookman MA, Longo DL. Lymphocytic lymphoma of intermediate differentiation. Mantle zone lymphoma. A distinct subtype of B-cell lymphoma. Hum Pathol 1987;18:877-80.

15 Melo JV, Catovsky D, Gregory WM, Galton DAG. The relationship between chronic lymphocytic leukaemia and prolymphocytic leukaemia. IV. Analysis of survival and prognostic features. Br J Haematol 1987;65:23-9.

16 Yunis JJ, Frizzera G, Oken MM, McKenna J, Theologides A, Arnesen M. Multiple recurrent genomic defects in follicular lymphoma. N Engl J Med 1987;316:79-84.

Requests for reprints to: Professor D Catovsky, MRC Leukaemia Unit, Royal Postgraduate Medical School, Ducane Road, London W12 0NN, England. 